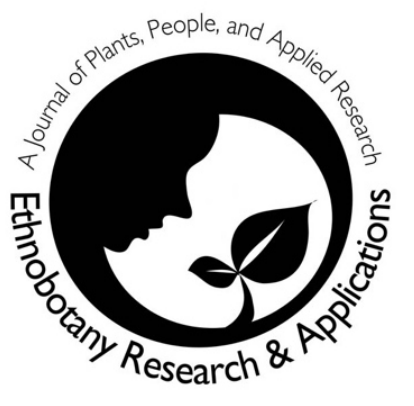

\title{
Developing a community-based enterprise: Nunatsiavut Inuit knowledge and perspectives on the use of medicinal plant Rhodiola rosea
}

Vanessa Mardones, Alain Cuerrier and Luise Hermanutz

\section{Correspondence}

Vanessa Mardones $^{1}$, Alain Cuerrier ${ }^{2^{*}}$ and Luise Hermanutz ${ }^{1}$

${ }^{1}$ Dept of Biology, Memorial University, St. John's, NL, Canada

2Montreal Botanical Garden, Plant Biology Research Institute (University of Montreal), Montreal, QC, Canada

*Corresponding Author: alain.cuerrier@umontreal.ca

Ethnobotany Research \& Applications 22:06 (2021)

\section{Research}

\begin{abstract}
Background: The medicinal plant Rhodiola (Rhodiola rosea), while valuable as an adaptogen in the global trade of natural health products, is not currently commercially sourced in eastern Canada. Rhodiola grows prolifically along the coast of Labrador (Canada), including rocky shorelines, sandy beaches, and up to the high tidal zone. Nunatsiavut Inuit in these remote areas have traditionally used Rhodiola as food and medicine; however, due to globalization and significant cultural changes, these communities are shifting from traditional activities towards new ventures. The cultivation of local Rhodiola presents an opportunity for a sustainable, community-based enterprise with economic and social benefits. It is critical to consider the unique local context when developing an enterprise intended to build capacity in participating communities as cultural context is a key factor determining the success of community-based enterprises.
\end{abstract}

Methods: To explore the potential for development of a natural health product based upon Labrador Rhodiola, semi-structured interviews and focus groups were conducted with Nunatsiavut Inuit Elders, youth, and community members.

Results: Participants reported both medicinal and food uses of the local Rhodiola, as well as unique insights into its growth and conservation. They were enthusiastic at the prospective social, economic, and health benefits of a community-based enterprise centered on cultivation and marketing of local Rhodiola, but concerned about the potential for over-harvesting, and wanted to ensure conservation of local populations.

Conclusions: A community-based enterprise centered on local Rhodiola cultivated in Nunatsiavut could benefit Nunatsiavut Inuit communities but would need to meet biocultural design criteria.

Keywords: Ethnobotany, Indigenous entrepreneurship, roseroot, Crassulaceae, Subarctic 


\section{Background}

In recent decades Rhodiola (Rhodiola rosea L.; Crassulaceae) has become significant in the global trade of natural health products, for its adaptogenic, antidepressive, and immunomodulating properties (Brown et al. 2002). The many uses of this plant have been well documented in numerous publications (Alm 2004, Cuerrier \& AmpongNyarko 2014). This plant has had a history of traditional use as both food and medicine among the Inuit (Cuerrier \& Hermanutz 2012, Cuerrier et al. 2019, Mardones 2019). Recently community members expressed interest in developing a sustainable enterprise based upon cultivation of Rhodiola native to coastal Labrador's Inuit lands of Nunatsiavut (Newfoundland and Labrador, Canada) utilizing biocultural design concepts (Davidson-Hunt et al. 2012). Cultivation of Rhodiola as a community-based enterprise based on traditional knowledge and cultural values in Nunatsiavut could diversify economic and social benefits to these communities.

There are however significant cultural differences among Inuit and First Nations attitudes towards commercialization of medicinal plants. For the First Nations, medicinal plants are generally considered a sacred gift of the creator for community use in healing. Therefore, commercialization can be highly controversial (Cuerrier et al. 2012b, Pengelly \& Davidson-Hunt 2012). The Inuit, unlike the First Nations, have launched commercial use of plant natural resources, for example through Makivik Corporation (Inuit development Corporation), and plants may be considered resources rather than sacred gifts. Products include caribou pâté, Avataq herbal tea, and Nunavik sea salt with local seaweeds.

Opportunity recognition, an important element of entrepreneurship, has been shown to be influenced by culture (Meis Mason et al. 2012), and can in turn influence enterprise development, particularly in Northern Indigenous communities (Dana \& Anderson 2007, Pengelly \& Davidson-Hunt 2012). Therefore, it is important to understand the cultural context of a proposed community enterprise based upon local medicinal plants, as this will influence its success and sustainability (Gavin et al. 2015). However, there is a scarcity of ethnobotanical research from the Eastern Canadian Arctic (Davis \& Banack 2012, Meis Mason et al. 2012), specifically with Nunatsiavut Inuit of Labrador. At the time of this study, no ethnobotanical work had been done in the town of Rigolet (Cuerrier \& Hermanutz 2012, Cuerrier et al. 2019; Downing \& Cuerrier 2011; Karst \& Turner 2011).

Among Nunatsiavut Inuit, referred to as Nunatsiavummiut, connection to the land is foundational to traditional knowledge and cultural identity (Cuerrier et al. 2012a, 2014, Downing \& Cuerrier 2011). Nunatsiavut is the first selfgoverning Inuit region in Canada, and its name means "Our Beautiful Land" in Inuktitut, the local language (Willox et al. 2012). Land-based activities such as hunting, fishing, and gathering are important in Inuit tradition for sustenance, cultural identity, and holistic well-being of body and mind. The northernmost Inuit settlement in Nunatsiavut, Nain (population 1,188), the community is remote, with limited access via boats and airplane, the latter being quite expensive and subject to grounding due to frequent bad weather, a reality on the Labrador coast (Rapinski et al. 2018). Likewise, Rigolet (population 306), the southernmost Inuit community in the world, is inaccessible by road but can be accessed by boat and small aircraft, or snowmobile in the winter. Many Canadian Inuit communities are similarly geographically isolated, and consequently, the cost of living in these communities is very high, access is limited, there are high levels of food insecurity, while job opportunities are limited, especially for youth (Davis \& Banack 2012, Meis Mason et al. 2012, Simon 2011). However, due to colonial history and globalization, these remote communities are significantly affected by global cultural influences. As early as 1771 , the first Moravian mission was established in Nain, affecting the culture and language of Labrador Inuit from an even earlier date than the Nunavik Inuit (Cuerrier et al. 2019). Fluency in Inuktitut in Nunatsiavut is $27 \%$ as of 2006 (Statistics Canada 2006), and the dialect of Inuktitut spoken in Rigolet, listed as a UNESCO endangered language, is maintained by only four people (Harper et al. 2012).

As a result of significant cultural changes in Labrador within the last generation (Willox et al. 2012, Willox et al. 2013), there is a generational gap and a lack of transmission of traditional knowledge and customary practices between Indigenous Elders and youth (Cuerrier et al. 2012a, Karst \& Turner 2011). Community research is an important tool to help bridge generational (Cuerrier et al. 2012a) and cultural gaps (Meis Mason et al. 2012), and to design research frameworks with local benefits that build cross-scale linkages (Berkes \& Davidson-Hunt 2007, Hindle \& Lansdowne 2005). Further, integration of traditional Inuit knowledge, known in Inuktitut as Qaujimajanngit (Meis Mason et al. 2012), is a cornerstone of development in the Canadian North. To inform culturally appropriate applications of traditional knowledge and practice and sustainable innovations, it is essential to integrate the knowledge and experience of the Elders, along with youth perspectives, into community development plans. If innovations based upon traditional knowledge are intended to bring economic and social benefits to the local community, then communities must be either lead the process or be consulted, to define and 
prioritize what benefits are of value within their unique biocultural context (Meis Mason et al. 2012). In Northern Indigenous community-based research conducted with Inuit in Nunavut (Meis Mason et al. 2012) and Pikangikum Anishinaabe in northwestern Ontario (Pengelly \& Davidson-Hunt 2012), product elicitation methods were found to effectively bridge cultural differences to explore community perspectives. It also informs development of products based upon traditional knowledge and/or biocultural resources, and identified the need to include youth perspectives, which are not usually considered.

Biocultural innovations that incorporate and build upon traditional knowledge and collaboration can increase community capacity, while also stimulating pride in traditional cultural heritage. We follow Davidson-Hunt's et al. (2017: 10) definition of 'biocultural innovations' as "New or traditional knowledge, resources, skills, and practices, which utilize biodiversity to support wellbeing in response to globalized change...". Davidson-Hunt et al. (2012: 33, Kuzivanova \& Davidson-Hunt 2017) use the expression 'biocultural design' to highlight "how endogenous innovation could support sustainable development in rural Indigenous and local communities". Using biocultural design within the context of a local enterprise has the power to address economic, social, cultural, and political realities of northern Indigenous peoples. This is especially powerful when the community is vested in land claims, self-determination and has to cope with cultural and land erosion. Co-design of a community enterprise based on traditional knowledge and cultivation of local Rhodiola in Nunatsiavut has the potential to confer economic benefits as well as a range of health benefits associated with customary practices and increased time on the land. Strengthening intergenerational connections with Inuit heritage and land in new and innovative ways will encourage biocultural resilience (Barthel et al. 2013, Berkes \& Davidson-Hunt 2007) as well as resource conservation (Gavin et al. 2015, 2018). Adhering to traditional ecological knowledge also minimizes the risk of overharvest inherent in commercial exploitation of natural resources, to inform locally appropriate conservation practices and precautions. Collaboration with Indigenous communities in the creation of entrepreneurship will stimulate the development of a social enterprise that respects and integrates cultural traditions and practices and ensures sustainable use of local biological resources. Such an enterprise would empower communities as economic agents (Hindle \& Lansdowne 2005), thus deepening biocultural resiliency. We suggest that using a biocultural design approach will trigger interests at different levels, locally and within Nunatsiavut, directly collaborating with beneficiaries (Davidson-Hunt et al. 2012; Kuzivanova \& Davidson-Hunt 2017).

This research examines the biocultural design process happening in the context of a valuable medicinal plant Rhodiola rosea used in several Nunatsiavut Inuit communities as a bridge from traditional knowledge to sustainable commercial enterprise. This project creates linkages among traditional knowledge, social enterprise, and sustainable economic activities, helping create community capacity to adapt and transform, for resilience within the social-ecological system. The objectives are to: 1) document traditional Nunatsiavut Inuit knowledge surrounding Rhodiola's use and ecology, and contextualize these findings with previous ethnobotanical interviews, and 2) solicit community perspectives on applying traditional knowledge for a commercial enterprise using interviews and focus groups, to determine a) if a natural health product based upon traditional knowledge is appropriate and acceptable to community members and their values, b) if there are any concerns, and c) how they envision distribution of benefits in the community.

\section{Materials and Methods}

Community meetings and round table sessions were held in two Nunatsiavut communities, Nain and Rigolet, to explore and document Inuit uses and traditional knowledge of Rhodiola, and to gauge community perspectives and goals on enterprise development centered around the cultivation and marketing of Rhodiola products. Fieldwork began in August 2012 in the communities of Rigolet and Nain $\left(54.1667^{\circ} \mathrm{N}, 58.4333^{\circ} \mathrm{W}\right.$ and $56.5422^{\circ} \mathrm{N}$, $61.6928^{\circ} \mathrm{W}$, respectively; see Figure 1). Prior to the interviews, ethics approval was obtained through the Interdisciplinary Committee on Ethics in Human Research (ICEHR) at Memorial University of Newfoundland. Free, prior, informed consent (FPIC) was obtained from all participants.

Focus groups were conducted in Nain with Inuit Elders in August 2013, and with Inuit youth in March 2015. The community of Nain was selected because there are a greater number of Elders in this community than in other communities in Nunatsiavut. Additionally, our research team has a longstanding working relationship with many members of the community due to previous community-guided research projects and an intergenerational plant workshop (Clark 2012, Cuerrier et al. 2012a). Previously, 37 ethnobotanical interviews were conducted with Nunatsiavut Inuit Elders by Clark (Cuerrier et al. 2019), and Cuerrier and Hermanutz (2012) in Nain 2009-2010. Our focus group was informed by the findings of these earlier interviews. Interview data gathered by Cuerrier et al. 
(2019) were filtered for respondents who mentioned "tulligunnak" or "roseroot" during the interview, and these respondents were then invited to participate in the subsequent Elder focus group in Nain.

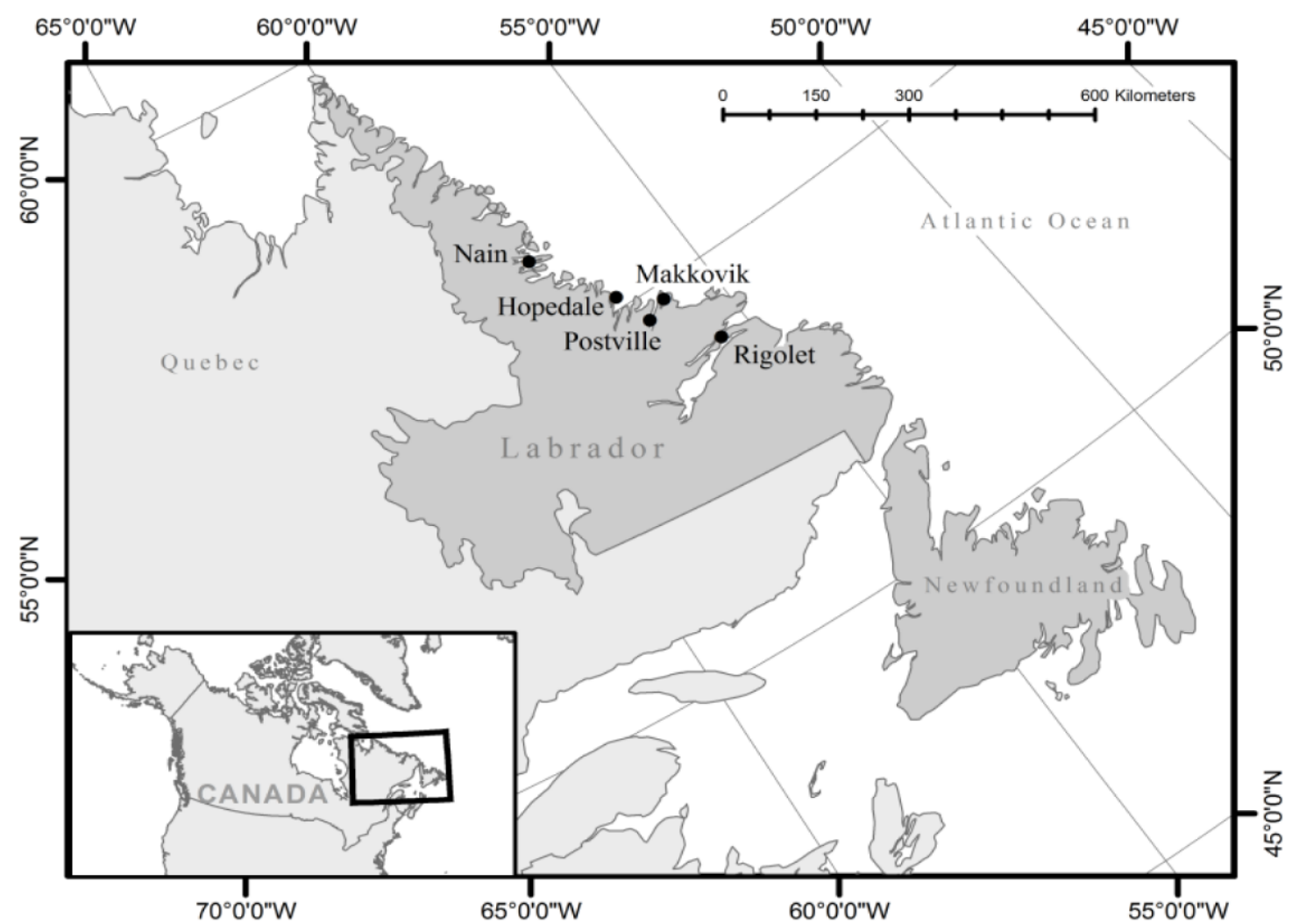

Figure 1. Map showing the location of all five Nunatsiavut communities, Labrador, Canada. Interviews and focus groups for this study were carried out in Nain and Rigolet.

In addition to these interviews, 13 Nunatsiavut Elders (nine female and four male) participated in the focus group that lasted approximately two hours. A semi-structured approach was used in facilitating the session. Discussions were structured around themes of plant use, habitat, harvesting, cultivation, and commercialization (with a focus on Rhodiola in particular). Photos and live specimens of Rhodiola were provided as object probes or aids to discussion. Representative voucher specimens have been deposited at the Marie-Victorin Herbarium (MT) of the Biodiversity Centre of the University of Montréal. Traditional knowledge of its uses, habitat, and cultivation was documented, as were opinions and perspectives on commercialization, concerns, and possible options. As some of the Elders were more comfortable speaking Inuktitut, a local Elder helped to facilitate as interpreter, while also contributing to the discussion with their own opinions. The focus group was audio recorded and notes taken. Out of respect for their knowledge, and in compliance with Nunatsiavut Government protocols, Elders were compensated for their time and participation.

Once the Elders had indicated their approval for a community enterprise based on Rhodiola, the views of youth were solicited, as they would be likely candidates for a community-based enterprise. The participation of youth (community members 25 and under) is often neglected in community-based biocultural research. In March 2015, a youth focus group was held in Nain with six participants under the age of 25 (four female and two male) to elicit their perspectives, opinions, and willingness to engage in such an endeavor. The purpose of the session was to introduce the youth of Nain to the potential for a community enterprise based upon Rhodiola, and to give them an opportunity to help steer the project and give input. Youth were recruited for the focus group by the community's youth coordinator, who also helped facilitate. Prior to the meeting, youth were asked to consult with Elders in their family and community, to solicit stories about traditional uses of plants that they could share during the focus group. Nain youth speak English as their first language, so an interpreter was not necessary. After icebreaker games and activities, youth participants were paired and asked to discuss what knowledge of medicinal plants they had gleaned from their Elders. A brief multi-media presentation was given, describing the 2013 Elder focus group, and providing background on the medicinal properties of Rhodiola, its commercial value, and the 
potential for local job opportunities. Follow-up discussion was then facilitated, encouraging youth to share their perspectives and/or concerns on using traditional Inuit knowledge for community enterprise, and to solicit their perspectives on benefit-sharing. Product elicitation has been shown to help bridge cultural gaps for exploration of product options (Meis Mason et al. 2012), so product samples were shared with youth to demonstrate possible natural health product derived from Rhodiola. In concluding, the youth were asked if and how they might like to be involved in the project, moving forward.

As no previous ethnobotanical work had been done in Rigolet, we conducted five semi-structured ethnobotanical and product elicitation interviews in August 2013, and an additional five interviews in March 2015, for a total of 10 interviews with Rigolet community members, (five female and five male informants). Plant specimens and photos were utilized as visual aids and product elicitation was utilized to explore community perspectives on potential Rhodiola-based products (Meis Mason et al. 2012, Pengelly \& Davidson-Hunt 2012). Samples of several commercial Rhodiola product forms (tincture and capsules) were displayed during half of the interviews (those conducted in 2015), and participants were invited to taste, smell, or try the products, and to read the packaging. Community open house meetings were held in Rigolet in 2013 and 2015 to facilitate open discussion of the idea of the enterprise. The project goals were discussed with local government officials (mayor or AngajukKâk) in both Rigolet and Nain.

Qualitative analysis of the focus group (13 Elders and six youth from Nain) and ethnobotanical interview data (10 community members from Rigolet) was approached in an inductive, iterative fashion; alternating between emergent readings of the data and etic use of existing models and theories in the literature to integrate the research observations into a broader scholarly context (Tracy 2013). An inductive approach has been used in other Northern Canadian Indigenous communities because it allows the research process to better adapt to fit the specific biocultural context (Pengelly \& Davidson-Hunt 2012). Previous qualitative ethnobotanical studies in Labrador and other Northern Canadian Indigenous communities have yielded descriptive, non-quantitative summaries of ethnobotanical applications and reported uses, with attention to details that situate the results within the specific biocultural context (Karst \& Turner 2011, Meis Mason et al. 2012, Pengelly \& Davidson-Hunt 2012). For the present research, data from ethnobotanical interviews previously conducted in Nain (Cuerrier et al. 2019) were pooled along with the ethnobotanical interviews in Rigolet, focus groups in Nain, and data from Makkovik (E. Oberndorfer, unpublished data). The resulting transcriptions were first reduced and reorganized, then filtered for references to Rhodiola, locally known as "tulligunnak" or "roseroot" (Flick 2014).

\section{Results}

\section{Nunatsiavut Inuit Uses of Rhodiola}

All uses of Rhodiola reported by Nunatsiavut Inuit in Nain, Rigolet, and Makkovik were pooled, categorized by part used, purpose, and method of application, and summarized (Table 1). Previous interviews conducted with Inuit Elders in Nain documented traditional Nunatsiavut Inuit uses of Rhodiola as food and medicine and showed that Nunatsiavut Inuit Elders have unique nomenclature to describe Rhodiola and its parts (Cuerrier \& Hermanutz 2012). The Rhodiola plant is referred to in the local Inuktitut as tulligunnak, and the below ground parts of Rhodiola are sometimes called utsuKammak (Cuerrier \& Hermanutz 2012). Inuit from Nunavik similarly call Rhodiola tallirunnaq or tullirunnaq, with the specific terms uqaujatuinnait when referring to the leaves and utsuqammat to refer to the roots (Cuerrier \& Elders of Kangiqsualujjuaq 2011, in Cuerrier et al. 2014). In Makkovik, only the term tulligunnak was reported; utsuKammak was not documented as a secondary term for Rhodiola, and no English names used for Rhodiola either (Oberndorfer et al. 2017).

Elders and community of Nain, Rigolet, and Makkovik reported food uses of all parts of Rhodiola except the flowers. In the 2013 focus group in Nain, Inuit Elders described traditional uses of Rhodiola, including new uses that had not previously been documented in the community (Table 1). Elders and community members noted that the aerial parts especially the new growth, were traditionally used as food, as a source of edible greens eaten in the spring. Some ate just the green leaves, alone or as a salad. The leaves are often dipped in molasses or another sweetener, sometimes also vinegar, according to taste. It was said that they used to harvest the tips (leaves and tops) when they were red to have as a trailside snack, for a burst of juice with sweet taste. In Makkovik, the early spring buds are compared to Brussel sprouts, but participants said the plants were not good to eat once they'd flowered, that they get too tough and that "they have a worm in them then" (Oberndorfer 2016; see Beaulieu et al. 2016 for a description of the gall mite in Rhodiola rosea). They would also cook the stalks with pork on special occasions. Several Elders in the focus group agreed that they had a separate word for the root itself, as found in previous interviews: utsuKammak, which was also said to be used raw or cooked as a food. Many noted that the roots taste 
sweet. One community member said that the root was eaten "like a little turnip". Another person said that they used to boil the root and also chew it fresh.

Table 1. Traditional uses and number of citations of Rhodiola (Rhodiola rosea) by Nunatsiavut Inuit documented in Nain, Rigolet, and Makkovik documented through interviews and a focus group.

\begin{tabular}{|c|c|c|c|}
\hline \multicolumn{4}{|c|}{ Nunatsiavut Inuit uses of Rhodiola rosea } \\
\hline Part used & Purpose & Method of use & $\begin{array}{l}\text { \# of } \\
\text { citations }\end{array}$ \\
\hline Green leaves & Food & Raw in salads; dipped in molasses and/or vinegar & 5 \\
\hline Tips (leaves and tops) & Food & $\begin{array}{l}\text { Out of hand as snack, especially new growth or when the } \\
\text { leaves appear red in spring/fall }\end{array}$ & 6 \\
\hline Buds (basal rosettes) & Food & $\begin{array}{l}\text { Eaten in early spring, "like little Brussel sprouts", when the } \\
\text { buds are still purple in color }\end{array}$ & 1 \\
\hline Stalks (all aerial parts) & Food & Cooked with pork & 1 \\
\hline Root & Food & Raw or boiled "like a little turnip" & 4 \\
\hline Root & $\begin{array}{l}\text { External } \\
\text { medicine }\end{array}$ & $\begin{array}{l}\text { Crushed and applied as poultice or compress for skin } \\
\text { conditions (esp. cuts and boils) }\end{array}$ & 5 \\
\hline Root & $\begin{array}{l}\text { External } \\
\text { medicine }\end{array}$ & Applied as compress/poultice for eye infections & 1 \\
\hline Whole plant & $\begin{array}{l}\text { External } \\
\text { medicine }\end{array}$ & Boiled (decoction) to make a soak for eczema & 1 \\
\hline $\begin{array}{l}\text { Tops (green leaves and } \\
\text { stems) }\end{array}$ & $\begin{array}{l}\text { External } \\
\text { medicine }\end{array}$ & $\begin{array}{l}\text { Applied directly to chapped hands after working at the fish } \\
\text { plant, to soothe and moisturize rough and dry skin }\end{array}$ & 1 \\
\hline Root & $\begin{array}{l}\text { Internal } \\
\text { medicine }\end{array}$ & Boiled and chewed to stimulate appetite & 1 \\
\hline Root & $\begin{array}{l}\text { Internal } \\
\text { medicine }\end{array}$ & Taken for sore throat & 1 \\
\hline $\begin{array}{l}\text { Whole } \\
\text { plant/unspecified }\end{array}$ & $\begin{array}{l}\text { Internal } \\
\text { medicine }\end{array}$ & Colds, especially head colds, stomach flu, toothache & 3 \\
\hline
\end{tabular}

All parts of the Rhodiola plant, except the flowers, were reportedly used as both internal and external medicine by community members in Nain, Rigolet, and Makkovik. In Makkovik the green leaves and stems are used to soothe chapped hands after processing fish (Oberndorfer et al. 2017). In Nain community members reported that the whole plant was boiled and used as a hand soak for eczema. The belowground parts (rhizome/root) are used medicinally as a remedy for fatigue, infection, colds, and toothache (Cuerrier \& Hermanutz 2012). The roots are crushed and used raw to make a poultice that is applied to cuts and boils, or they are cooked and made into a poultice as a remedy for eye infections. Elders said fresh or dried root could be applied as a poultice to boils (skin conditions), and that it could be used for healing cuts. The boiled root was chewed as an appetite stimulant, and a community member said it was used for stomach flus and bugs. Several community members said that it was good for colds, especially a head cold.

\section{Traditional Ecological Knowledge of Rhodiola Habitat and Cultivation}

Elders and community members had observed Rhodiola growing in Nunatsiavut on islands and shorelines, and they had unique insight into the local habitat of Rhodiola and prospects for cultivation. An interviewee from Rigolet observed that as soon as the ice melts, "they are the first plant you see in the spring on the beach and shorelines, popping up like a little rose. And they are one of the last to die back in fall." In the wild they observed Rhodiola growing in sandy, cool places, as well as in cracks and crevices of rocks and cliffs. All interviewees observed Rhodiola growing on islands, sometimes among birds' nests, and speculated that gull and duck droppings aided its growth. It was also noted that birds eat the seeds, and black bears and gulls eat the plants. One interviewee observed that Rhodiola "needs some of its own soil to grow". In transplanting, it was said that there is less risk of leaving a vital part of the plant in the ground if the plant is transplanted after dormancy. Some Nain residents had tried 
transplanting Rhodiola without success and speculated that it could be due to dampness, or because the roots were too small. However, several interviewees in Rigolet said that Rhodiola transplanted easily to their home gardens and thrived as a low maintenance ornamental.

Recently, participants have expressed concern as, "The tulligunnak is not as thick as it used to be, now the grass has taken over", and within the last few years since this research has begun, "rising waters and rough seas are affecting the shoreline tulligunnak populations". Former AngajukKâk/Mayor of Rigolet observed that this is happening all along Groswater Bay (outside of Rigolet), and the effect might be even more pronounced outside the bay where there is "bigger water" [i.e. rising waters and rough seas] (Wolfrey, pers. comm.), and predicts that in a few years, those shoreline populations will be gone. She suggests that these at-risk populations could be candidates for transplantation and/or for early product production while the cultivated crops are getting established. Environmental concerns were also voiced in Makkovik, where participants had limited their harvest of tulligunnak due to concerns of pollutants contaminating the plants in town, and the danger of traveling outside of town in Spring [as a result of uncertain ice conditions due to recent climate fluctuations] (Oberndorfer 2016). In Makkovik it was also noted that traditional harvesting practices could benefit local Rhodiola plants; by harvesting the edible buds in spring and prolonging the vegetative growth state, flowering is delayed, and plant growth is more vigorous (Oberndorfer 2016).

\section{Perspectives on Community Enterprise and Distribution of Benefits}

Elders were surprised to learn that a local, traditionally used plant was valuable in the global commercial trade of natural health products. They were enthusiastic at the prospect of jobs for young community members that would also perpetuate traditional Inuit ties to the land, and they indicated unanimous support for the proposed community-based enterprise centered around cultivation and marketing of Rhodiola. Community members recognized this as an opportunity for the youth to learn about the plants, to counter the loss of traditional botanical knowledge, and as an opportunity to generate fulfillment and pride from growing gardens. It was noted that with the high cost of living and the scarcity of jobs, economic benefits would be quite welcome, although many community members anticipated this opportunity would bring only moderate economic benefits, while much of the benefit would be intangible. Several noted that it would be essential to recruit a knowledgeable program manager for the project to be successful. Everyone agreed that economic benefits from a commercial enterprise based upon local Rhodiola should stay in the community. Many felt that the benefits could be directed towards student programs, particularly those that link Elders and youth to help sustain traditional plant knowledge. These responses reinforce the strong biocultural design components of this project; the potential for collaboration is very strong in all the communities.

Youth focus group participants were very enthusiastic about the prospect of a community enterprise based upon a local medicinal plant. They felt there was significant potential for community-wide benefits that would make it worth investing in, even if only a few people gained employment. One participant had observed interest in gardening expressed in the community, and that this project could therefore address community goals. The students strongly supported this approach and noted that the enterprise would benefit the health of the community on multiple levels, such as by getting out on the land and gardening, which would benefit the physical and mental health of youth and community members. It would also bring greater attention to the medicinal and antidepressant properties of the plant, which were not widely known or employed among the greater community, despite the prevalence of depression the youth noted during the discussion. They also felt that benefits from an enterprise based upon Rhodiola should be distributed within the community, and particularly directed towards student programs. They felt that if the youth were planting and tending community gardens, then it would be fair to invest the benefits in the youth programs. In the words of one Nunatsiavut youth participant,

If we find other people to get involved with it, if we got together, it could actually become real. It would be a good thing to do with the student program. Even if it was just ... [to] educate people on the importance of it, they'll know then. Because some people don't even know, I didn't know before, I knew you could eat it, but I didn't know all this, it's like really cool and if other people knew that too...

\section{Concerns and Questions Regarding a Community-Based Enterprise}

Asked if there were any concerns, Elders thought that the garden could get vandalized by wildlife and/or people. They wondered if the garden would be looked after well enough to make it worthwhile. They were moderately concerned about the potential for misuse of the solvents to be used for extraction (alcohol) if tinctures were to be 
produced within the community. However, there was general consensus that with adequate measures this would not be a problem, and that the enterprise could bring a host of benefits to the community.

Community members also expressed concerns regarding natural resource conservation, and particularly the need to better understand how selective harvesting of wild Rhodiola to start the gardens might affect local populations. There were concerns that wild Rhodiola might be overharvested due to greed, and that it would be difficult to monitor or regulate wild harvesting. However, as a former AngajukKâk/Mayor observed, pressure on wild populations is already occurring due to erratic weather and shoreline erosion, such that some populations are already decreasing.

Another concern expressed by community members was the possibility of equal partnership between outsiders and local community. One community member stated that the research process is an ideal learning process involving both sides, that Inuit can learn from Kallunâk (outsiders) as much as the reverse. It is important to make community members part of the decision-making process mirroring the approach advocated by Gavin et al. (2015) and Davidson-Hunt et al. (2012).

When youth were asked if they had any concerns regarding a community enterprise based on Rhodiola, one youth wondered who would own and manage the enterprise. Asked how she would ideally envision such an enterprise in her community, she pointed out that Nunatsiavut means "Our Beautiful Land" in Inuktitut, and that the plants growing on the land likewise are an asset that belongs to the whole community, and therefore she would like to see the whole community involved in the enterprise.

The AngajukKâk/Mayor of Rigolet shared many ideas during an open meeting, including ways to integrate the project with regional funding sources and Aboriginal business networks. This discussion underlined some of the principles set forth in Gavin et al. (2015) and Kuzivanova and Davidson-Hunt (2017), namely, the acknowledgment of multiple objectives (employment, intergenerational transfer of knowledge, and conservation of a culturally important species) and stakeholders (Elders, youth, community authorities, land corporation, etc.).

\section{Discussion}

Ethnobotanical knowledge is contextual and interconnected; embedded in culture and place, and the perception and success of entrepreneurial opportunities based on traditional knowledge innovation is therefore dependent upon the biocultural context (Pengelly \& Davidson-Hunt 2012, Meis Mason et al. 2012). Indigenous communities have suffered a range of cultural losses, with detrimental effects on customary practices and for intergenerational knowledge transmission (Turner et al. 2008). Plants play a vital role in connecting customary values and practices for community well-being, in addition to their utilitarian applications as food and medicine (Oberndorfer et al. 2017). The Nagoya Protocol in the Convention on Biological Diversity (Secretariat of the Convention on Biological Diversity 2011) mandates that there be equitable sharing of benefits accrued from utilization of biological resources engaging the community in participatory, values-based discussions (Davidson-Hunt et al. 2012, Turner et al. 2008) to ensure Indigenous communities have an active role in management of biocultural resources and community self-determination. Therefore, it was important to have open dialogue with Nunatsiavut community members about the traditional knowledge (Qaujimajanngit) of Rhodiola and its potential applications for community enterprise to ensure biocultural conservation (Gavin et al. 2015, Maffi \& Woodley 2010). Nunatsiavut Inuit Elders and community members report medicinal, and food uses of Rhodiola, some of which are unique to Nunatsiavut, consistent with the findings of Cuerrier et al. (2019). Elders and community members also shared unique traditional knowledge of Rhodiola's ecology and habitat, which they have gained through extended observation of the local environment, as documented in another Labrador community, Charlottetown (Karst \& Turner 2011).

Opportunity recognition was observed in both Inuit youth and Elder focus groups as well as in individual interviews, with fewer reservations cited compared with other Canadian Indigenous communities (Pengelly \& Davidson-Hunt 2012, Meis Mason et al. 2012). Community members from the youth to the Elders were enthusiastic about the potential benefits of an enterprise based on a local medicinal plant, while still maintaining a pragmatic outlook on possible economic outcomes, reflecting an exciting example of biocultural design. However, there were some differences in the perspectives of Elders and youth when it came to the benefits that the enterprise could bring to the community. Elders anticipated that the enterprise would bring jobs for the youth in the community, and that an enterprise based upon a traditional medicinal plant would be valuable for perpetuating customary practices such as time on the land. Inuit youth, however, observed and articulated a wider range of benefits that could arise from the enterprise, for both physical and mental health, as well as economic and social benefits within the 
community. The youth perspective on the benefits of a community enterprise is consistent with the findings of Ratten and Dana (2015) that "social entrepreneurship is a key part of entrepreneurial activity for Indigenous people because of its linkage to the community and overall well-being of society." This is also echoed in the biocultural approach advanced by McCarter et al. (2018), in which these authors underline environmental health according to place-based observations with positive impacts on the well-being of the community. As a social enterprise, the youth felt this project could provide a number of opportunities for community members. These included a) more gardening activities, while also perpetuating customary practices, b) educating community members more widely on the health benefits of this traditional plant, and c) using it as a natural health product. This is especially relevant giving the high level of depression documented in Nunatsiavut, due in part to the effects of climate change (Willox et al. 2013). Youth also recognized the economic benefits of the enterprise and showed interest in the jobs and training this would entail and felt that the economic benefits could help support local student programs. Given the troublingly high levels of unemployment among Aboriginal youth in Canada and the high levels of school attrition rates (Abele \& Delic 2014), community enterprises which provide training, engagement and employment for youth could be extremely beneficial.

Product elicitation methods were useful to explore community members' thinking on an opportunity for a community-based enterprise, as well as to gauge the cultural appropriateness of product options, consistent with the findings of Meis Mason et al. (2012) in another Canadian Inuit community. However, Nunatsiavut Inuit Elders and community members stated no preference amongst potential Rhodiola product forms, whereas Elders of the Pikangikum First Nation, another Northern Canadian Indigenous community, preferred products of lower degrees of transformation (Pengelly \& Davidson-Hunt 2012).

Reciprocity is an important value in Canadian Indigenous communities (Turner 2014) and was expressed by Nunatsiavut Inuit community members. It has been commonly observed by Nunatsiavut residents that researchers who conduct research in these communities, often do not incorporate the local knowledge in their studies, nor do they return to report on results (Cuerrier unpublished data). However, it is important to integrate traditional knowledge into collaborative research to ensure the biocultural design of such social enterprises (Davidson-Hunt et al. 2017). Traditional knowledge will help inform the conservation of local Rhodiola, which is becoming a more pressing issue with the recently observed decreases in shoreline populations (Wolfrey pers. comm.; Gavin et al. 2015, McCarter et al. 2018). Nunatsiavut Inuit described a need to better understand the factors that affect Rhodiola's reproduction, and how harvesting the local Rhodiola for propagation would affect the wild populations. Concerns expressed by Nunatsiavut community members for conservation of Rhodiola in the wild are very real; similar concerns have been documented in other Canadian communities (Meis Mason et al. 2012, Turner 2014). In the case of the anti-cancer drug Taxol, harvested from the Pacific yew tree, unsustainable commercial extraction of a traditionally used medicine led to overharvest, making this medicine unavailable to local Indigenous peoples (Turner 2014). Since Rhodiola is already threatened due to overharvest in Russia and parts of Europe, especially in Bulgaria, where it is critically endangered (Allen et al. 2014, Cuerrier et al. 2014), it is important to understand the issues affecting its conservation in North America as well. Rhodiola is critically imperiled, presumed extirpated, or extirpated in three states in the US due to overharvesting (Cuerrier et al. 2014). More research needs to be done to understand the conservation science of Nunatsiavut Rhodiola populations; how shoreline populations are being affected by climate change, tidal fluctuations, and shifts in species composition, and what effect selective harvesting for cultivation would have on already decreasing populations (Ticktin 2004). While community members in Rigolet found Rhodiola transplanted easily into home gardens, Elders in Nain had been largely unsuccessful in attempts to bring wild Rhodiola into gardens, pointing to the need to learn more about the factors that support successful cultivation of Rhodiola in Nunatsiavut. Other factors such as land availability, youth availability, and funding will also influence the communities' decisions to establish Rhodiola gardens in Nunatsiavut, with guidance from the Nunatsiavut government. Using outside sources of Rhodiola to be sold as cultural product to decrease conservation challenges was not considered as viable alternative, as the community members were interested in supporting community jobs. Partnerships with other Inuit communities could be considered in the future. This plant has been grown from wild harvested plants in numerous places such as Alberta (AARGO; Canada; Ampong-Nyarko et al. 2005), Russia, Germany, Finland (Galambosi 2006), Poland (Furmanowa et al. 1999), and Italy (Aiello et al. 2010), and may have experience to share.

These elements (collaboration, local knowledge and resources, community values, innovation) form an inclusive framework based on biocultural design, which protects traditional knowledge, promotes self-determination, and ensures biodiversity conservation and economic benefits. Elders and youth pointed out the importance of linking small economic enterprises to culture. The impacts of such a biocultural design approach would be multifold and 
some of the principles behind the concept, such as linkages among age groups and to culture, were cited by the different members of the communities, as per beneficiaries in the sense of Davidson-Hunt et al. (2012).

\section{Conclusion}

Abrupt and disruptive changes in the social and ecological fabric of Indigenous communities can present significant challenges for the resilience of remote northern people and their culture. For Inuit living in the eastern Canadian Subarctic, climate change's effects on the local environmental conditions have a significant impact on traditional subsistence activities, increasing the risks associated with traveling on the land and across frozen water to secure resources (Downing \& Cuerrier 2011; Rapinski et al. 2018). A resilient biocultural system buffers change and uncertainty, providing adaptive capacity while also maintaining biocultural diversity and conservation (Folke 2006, Holling 2004). By using a biocultural design approach, Indigenous societies develop and sustain pathways for adapting to dynamic and changing environments, as well as embracing their land, their culture, and promoting self-determination. Recognizing that the unique local context will influence the success of a community-based enterprise (Pengelly and Davidson-Hunt 2012), the present research will inform the opportunity analysis of a community enterprise based on local medicinal plants in Nunatsiavut. By integrating intergenerational knowledge, experience, and perspectives, the resulting cross-scale linkages will inform innovation based upon traditional knowledge of a local medicinal plant, building community capacity and thus meeting the goals of a biocultural design approach.

\section{Declarations}

List of abbreviations: ICEHR, Interdisciplinary Committee on Ethics in Human Research; FPIC, Free Prior Informed Consent

Ethics approval and consent to participate: Research approval was obtained from the Nunatsiavut Government. Research methods were approved by the Memorial University of Newfoundland Interdisciplinary Committee on Ethics in Human Research. (ICEHR\# 20130328-SC). Informed consent was obtained from each participant.

Consent for publication: Not applicable.

Availability of data and materials: The PhD thesis has been deposited at the Memorial University of Newfoundland Centre of Newfoundland Studies. Data (interviews, focus group, etc.) have been kept confidential.

Competing interests: None declared.

Funding: Partial funding was provided by an NSERC - ArcticNet Centre of Excellence Award and a Harris Centre Applied Research grant granted to Hermanutz and Cuerrier. VM was funded by Memorial University and ArcticNet. Authors' contributions: All three authors participated in fieldwork and focus groups. VM and AC did the individual interviews. The manuscript was written by $\mathrm{VM}, \mathrm{AC}, \mathrm{LH}$.

\section{Acknowledgements}

We are grateful to the people of Nunatsiavut for welcoming us into the communities of Rigolet and Nain, and for sharing their knowledge, experience, and insight. We would especially like to thank the Elders of Nain who participated: Verona Ittulak, Annie Lampe, Julius Merkuratsuk, Lucas Ittulak, Adam Lidd, Sabina Lidd, Mary Dicker, Jessie Ford, Christine Baikie, K. Naeme Merkuratsuk (Interpreter as well), Katie Winters, Julius Ikkusek, and Timo Townley; as well as the youth of Nain: Caroline Nochasak, Brianna Brown, Megan Dicker, Simeonie Merkuratsuk, Johnathan Lidd, and Sarah Karpik (facilitator); and the community members of Rigolet that participated in interviews: Arch Flowers, Charlotte Wolfrey, Derrick Pottle, Wendy Pottle, Garmel Rich, Liz Tooktoshina, Richard Rich, Sarah Baikie, and Jack Shiwak. We are also grateful to Erica Oberndorfer for sharing pre-publication data collected under permit working with plant mentors in Makkovik.

\section{Literature Cited}

Abele F, Delic S. 2014. Aboriginal youth employment in Northern Canada: Knowledge synthesis report. Carleton Centre for Community Innovation, Ottawa.

Aiello DN, Scartezzini F, Vender C. 2010. Rhodiola rosea. Dalla raccolta spontanea alla coltivazione. Erboristeria Domani 7:43-49.

Allen D, Bilz M, Leaman DJ, Miller RM, Timoshyna A, Window J. 2014. European Red List of medicinal plants. Publications Office of the European Union, Luxembourg.

Alm T. 2004. Ethnobotany of Rhodiola rosea (Crassulaceae) in Norway. SIDA 21:324-344. 
Ampong-Nyarko K., Zhang N. 2007. New crop development crop diversification centre North. In Alberta 2007 Specialty crop report. Edited by C Su. Alberta Agriculture, Food and Rural Development, Edmonton, Alberta, Canada, Pp. 26-35. https://www1.agric.gov.ab.ca/\$department/deptdocs.nsf/all/sdd11803/\$file/report2007.pdf? OpenElement (accessed July 15, 2021)

Barthel S, Crumley C, Svedin U. 2013. Bio-cultural refugia - Safeguarding diversity of practices for food security and biodiversity. Global Environmental Change 23:1142-1152.

Berkes F, Davidson-Hunt IJ. 2007. Communities and social enterprises in the age of globalization. Journal of Enterprising Communities: People and Places in the Global Economy 1:209-21.

Brown RP, Gerbarg PL, Ramazanov Z. 2002. Rhodiola rosea: A phytomedicinal overview. HerbalGram 56:40-52.

Cuerrier A, Ampong-Nyarko K, eds. 2014. Rhodiola rosea. CRC Press, Boca Raton, Florida.

Cuerrier A, Clark C, Norton CH. 2019. Inuit plant use in the eastern subarctic: comparative ethnobotany in Kangiqsualujjuaq, Nunavik and Nain, Nunatsiavut. Botany 97:271-282.

Cuerrier A, Hermanutz L. 2012. Our plants... our land: Plants of Nain and Torngat mountains basecamp and research station (Nunatsiavut). Institut de recherche en biologie végétale \& Memorial University, Montreal.

Cuerrier A, Downing A, Johnstone J, Hermanutz L, Siegwart-Collier L, Elders \& Youth Participants of Nain and Old Crow. 2012a. Our plants, our land: Bridging aboriginal generations through cross-cultural plant workshops. Polar Geography 35:195-210.

Cuerrier A, Downing A, Patterson E, Haddad PS. 2012b. Aboriginal antidiabetic plant project with the James Bay Cree of Québec: An insightful collaboration. Journal of Enterprising Communities: People and Places in the Global Economy 6:251-270.

Cuerrier A, Tendland Y, Rapinski M. 2014. Ethnobotany and conservation of Rhodiola species. In Rhodiola rosea, edited by A. Cuerrier and K. Ampong-Nyarko, pp. 35-63. CRC Press, Boca Raton, Florida.

Dana LP, Anderson RB. 2007. International handbook of research on indigenous entrepreneurship. Edward Elgar Publishing, Cheltenham.

Davidson-Hunt IJ, Idrobo CJ, Janzen A, Kuzivanova V, Lizáraga P, Robson JP, Turner KL, Vacaflores C. 2017. Biocultural design research guide: Innovation in small-scale food systems. Taller BCD Workshop. AttributionShareAlike 4.0 International, Creative Commons. doi: 10.13140/RG.2.2.13445.65765

Davidson-Hunt IJ, Turner KL, Te Pareake Mead A, Cabrera-Lopez J, Bolton R, Idrobo CJ, Miretski I, Morrison A, Robson JP. 2012. Biocultural design: A new conceptual framework for sustainable development in rural indigenous and local communities. S.A.P.I.E.N.S. 5:33-45.

Davis JD, Banack SA. 2012. Ethnobotany of the Kiluhikturmiut Inuinnait of Kugluktuk, Nunavut, Canada. Ethnobiology Letters 3:78-90.

Downing A, Cuerrier A. 2011. A synthesis of the impacts of climate change on the First Nations and Inuit of Canada. Indian Journal of Traditional Knowledge 10:57-70.

Flick U, ed. 2014. The SAGE handbook of qualitative data analysis. Sage, London.

Folke C. 2006. Resilience: The Emergence of a perspective for social-ecological systems analyses. Global Environmental Change 16:253-267.

Furmanowa M, Kedzia B, Harwitch M., Kozlowski J, Krajewska-Patan A, Mscisz A, Jankowiak J. 1999. Phytochemical and pharmacological properties of Rhodiola rosea L. Herba Polonica 45:108-113.

Galambosi B. 2006. Demand and availability of Rhodiola rosea L. raw material. In medicinal and aromatic plants. Edited by RJ Bogers, LE Cracker, D Lange. Springer, Wageningen, The Netherlands, Pp. 223-236.

Gavin MC, McCarter J, Mead A, Berkes F, Stepp JR, Peterson D, Tang R. 2015. Defining biocultural approaches to conservation. TREE 30:140-145.

Gavin MC, McCarter J, Berkes F, Mead A, Sterling EJ, Tang R, Turner NJ. 2018. Effective biodiversity conservation requires dynamic, pluralistic, partnership-based approaches. Sustainability 10:1-11. 
Harper S., Edge V, Cunsolo Willox A, Rigolet Inuit Government. 2012. Changing climate, changing health, changing stories' profile: Using an EcoHealth approach to explore impacts of climate change on Inuit Health. Ecohealth 9:89101.

Hindle K, Lansdowne M. 2005. Brave spirits on new paths: Toward a globally relevant paradigm of indigenous entrepreneurship research. Journal of Small Business \& Entrepreneurship 18:131-141.

Holling CS. 2004. The backloop to sustainability. In Navigating social-ecological systems: Building resilience for ocmplexity and change. Edited by F Berkes. Cambridge University Press, Cambridge, USA, Pp.33-47.

Karst AL, Turner NJ. 2011. Local ecological knowledge and importance of Bakeapple (Rubus chamaemorus L.) in a Southeast Labrador Métis community. Ethnobiology Letters 2:6-18.

Kuzivanova V, Davidson-Hunt IJ. 2017. Biocultural design: Harvesting Manomin with Wabaseemoong Independent Nations. Ethnobiology Letters 8:23-30.

Maffi L, Woodley E. 2010. Biocultural diversity conservation: A global sourcebook. Earthscan, New York, USA.

Mardones, V. 2019. Ethnobotanical entrepreneurship for indigenous biocultural Rresilience: Rhodiola rosea in Nunatsiavut. Doctoral dissertation. Memorial University of Newfoundland, St.John's, NFLD.

McCarter J, Sterling EJ, Jupiter SD, Cullman GD, Albert S, Basi M, Betley E, Boseto D, Bulehite ES, Harron R, Holland PS, Horning N, Hughes A, Jino N, Malone C, Mauli S, Pae B, Papae R, Rence F, Revo O, Taqala E, Taqu M, Woltz H, Filardi CE. 2018. Biocultural approaches to developing well-being indicators in Solomon Islands. Ecology and Society 23 (1):32. https://doi.org/10.5751/ES-09867-230132

Meis Mason A, Anderson R, Dana L. 2012. Inuit culture and opportunity recognition for commercial caribou harvests in the bio economy. Journal of Enterprising Communities: People and Places in the Global Economy 6:194-212.

Oberndorfer E. 2016. The shared stories of people and plants: Cultural and ecological relationships between people and plants in Makkovik, Nunatsiavut (Labrador, Canada). Unpublished Doctoral Dissertation, Department of Geography, Carleton University, Ottawa, Canada.

Oberndorfer E, Winters N, Gear C, Ljubicic G, Lundholm J. 2017. Plants in a "sea of relationships": Networks of plants and fishing in Makkovik, Nunatsiavut (Labrador, Canada). Journal of Ethnobiology 37:458-477.

Pengelly R.D, Davidson-Hunt IJ. 2012. Partnerships towards NTFP development: Perspectives from Pikangikum First Nation. Journal of Enterprising Communities: People and Places in the Global Economy 6:230-250.

Rapinski M, Payette F, Sonnentag O, Herrmann TM, M-JS Royer M-JS, Cuerrier A, Siegwart Collier L, Hermanutz L, Guanish G, Elders of Kawawachikamach, Elders of Kangiqsualujjuaq, Elders of Nain. 2018. Listening to Inuit and Naskapi: a story of climate change supported by meteorological measurements and climate fields in Eastern Subarctic Canada. Regional Environmental Change 18:189-203. doi:10.1007/s10113-017-1188-3

Ratten V, Dana L. 2015. Indigenous food entrepreneurship in Australia: Mark Olive 'Australia's Jamie Oliver' and Indigiearth. International Journal of Entrepreneurship and Small Business 26:265-279.

Secretariat of the Convention on Biological Diversity. 2011. Nagoya Protocol on access to genetic resources and the fair and equitable sharing of benefits arising from their utilization. Secretariat of the Convention on Biological Diversity, Montreal, Canada.

Simon M. 2011. Canadian Inuit: Where we have been and where we are going. International Journal66:879-891.

Statistics Canada. 2006. Aboriginal peoples in Canada in 2006: Inuit, Métis and First Nations, 2006 Census. Statistics Canada Catalogue no. 97-558-XIE. Ottawa. Analysis

Series, 2006 Census. http://www12.statcan.ca/census-recensement/2006/as-sa/97-558/index-eng.cfm (accessed May 6, 2016)

Ticktin T. 2004. The ecological implications of harvesting non-timber forest products. Journal of Applied Ecology 41:11-21.

Tracy SJ. 2013. Qualitative research methods: Collecting evidence, crafting analysis, communicating impact. John Wiley \& Sons, Hoboken, USA. 
Turner NJ. 2014. Ancient pathways, ancestral knowledge: Ethnobotany and ecological wisdom of indigenous peoples of northwestern North America. McGill-Queen's Press-MQUP, Montreal \& Kingston, Canada.

Turner NJ, Gregory R, Brooks C, Failing L, Satterfield T. 2008. From invisibility to transparency: Identifying the implications of invisible losses to First Nations communities. Ecology and Society 13:7.

Willox AC, Harper SL, Ford JD, Landman K, Houle K, Edge VL. 2012. From this place and of this place: Climate change, sense of place, and health in Nunatsiavut, Canada. Social Science \& Medicine 75:538-547.

Willox AC, Harper SL, Ford JD, Edge VL, Landman, Houle K, Blake S, Wolfrey C. 2013. Climate change and mental health: An exploratory case study from Rigolet, Nunatsiavut, Canada. Climate Change 121:255-270. 